\title{
Forest regeneration surveys: Design, data collection, and analysis
}

\author{
by David G. Brand ${ }^{1}$, Donald G. Leckie, and Edward E. Cloney
}

\begin{abstract}
Regeneration surveys have always been looked on as a necessary evil in silviculture. Huge amounts of data have been collected, only to answer simple questions or to be filed and never used. This paper addresses the possibility of changing regeneration surveys from simple legislative requirements, into components of the forestry information system. Current technology allows the development of sophisticated decision support systems, and this changes the whole perspective on information needed from regeneration surveys. Depending on the level of information needed, ground surveys or aerial surveys can be used. The types of information available from different survey systems are described, and two case studies are presented. In one, regenerating stands are assessed using an intensive groundbased survey and, in the second, the MEIS (Multi-spectral, Electro-Optical Imaging Scanner) is used to identify stocking in young plantations. It is concluded that surveys must be designed by working backwards from the decisions to be made, to the information needed to make those decisions, to the data needed to provide that information.
\end{abstract}

\section{Résumé}

L'estimation de la regeneration forestiere necessite, un moment donne, la description des ressources pour une raison quelconque. En general, le but est d'evaluer la regeneration dont le degre de succes est compare aux normes etablies. Les normes actuellement utilisees telles que la plantation en croissance libre exigent la definition des criteres par lesquels une certaine norme doit etre examinee avant de pouvoir dresser un plan de systemes d'evaluation. Les releves sur le terrain ou aeriens (teledetection) peuvent etre utilises, dependant du niveau souhaite de la description. Dans le present article sont traites les types de reseignements disponibles provenant de differents systemes d'evaluation ainsi que deux etudes de cas. Lors de la premiere etude, une serie de quatre coupes a blanc a ete evaluee a l'aide d'un systeme d'information sur le terrain. Pendant le seconde, on se servait d'un capteur imageur electro-optique multibande (MEIS) pour identifier la densite relative de jeunes plantations. Selon les resultats, on arrive a la conclusion que les releves aeriens sont probablement bein utilies dans les forets boreales qui sont soumises a un amenagement extensif. Toutefois, les releves sur le terrain demeurent importants dans les forets qui subissent un amenagement intensif.

\section{Introduction}

An important type of forest survey is regeneration assessment. Its general purpose is to evaluate stocking, competition problems, and composition of new stands. These surveys are usually prescriptive in the sense that a decision is made on whether the area is successfully established to the desired species and free-growing. The survey leads, whether through comparison with standards or by data analysis, to the ability to prescribe a treatment where necessary. Regeneration surveys are, however, time consuming and lead to a large amount of data that must be evaluated by forest managers. As most forest managers are too busy to spend time examining the results of regeneration surveys in detail, most of the information goes unused. If we are ever to make significant use of this type of data, the whole concept of the regeneration survey must be redesigned to become part of an information system or decision support system. This paper will examine current approaches to survey design and methodology, and will describe new methods that may be available to forest managers in the coming years.

\section{Regeneration Surveys}

Formal regeneration surveys evolved from a need to classify forest land that had been logged or burned. In most cases, the objective was to determine if planting was needed to restock the area concerned. Regeneration surveys generally concentrated on measuring stocking or the degree to which the area would be fully occupied by trees as the stand developed. Areas would be surveyed at some time after harvest

Forestry Canada, Petawawa National Forestry Institute, Chalk River, Ont. K0J $1 \mathrm{JO}$.

${ }^{1}$ Present address, Forestry Canada, Science and Sustainable Development Directorate, 351 St. Joseph Blvd., Hull, Québec K1A 1 G5. or fire. Usually, where planting was anticipated, the survey would be done shortly after harvesting, and plantable spots would be determined as part of the survey. In areas where natural regeneration was anticipated, the survey might be done 5 to 7 years after disturbance. The regeneration survey would lead to a new label on the forest cover map for the area, usually including the tree species composition, stocking, and age class. Areas not meeting some minimum stocking standard would be classed as NSR (not satisfactorily restocked.).

In the past, most regeneration surveys were field-based, using fixed-area plots. Areas to be surveyed would be delineated and systematically surveyed. Attempts were usually made to pre-stratify the areas sampled based on a 'walk-through' survey. Secondary information concerning weed competition, insect or animal damage, and site conditions would be collected as comments or rated on survey forms. In most cases, the information was manually collected and tabulated and led to simple statistics such as mean stocking, planting difficulty, and species composition. These surveys were adequate for identifying the presence of regeneration, but did little to infer its success.

The most common problem with regeneration surveys was their inability to recognize the potential of regeneration to succeed in forming a new crop of trees. In many cases, foresters found that areas surveyed and classified as stocked were, in fact, overgrown by weed species. So common was this problem that a new type of standard emerged in several provinces: the concept of free-growing regeneration. This standard specified that areas would have to be satisfactorily stocked with acceptable regeneration and free from excessive non-crop competition (Armson et al. 1980; B.C. Ministry of Forests 1990; N.B. Department of Natural Resources 1982; Curry 1990). More recent surveys have 
been designed to judge this free-growing status, usually by visually assessing the competition level around trees as part of the regeneration survey.

Regeneration survey methods are constantly evolving. The changes over time relate to increasing demands for information by decision-makers, the continual search for greater efficiency in data collection and analysis, usually via the application of new technologies, and a need for flexibility in survey design (Corbett and McCulligh 1990, Pearce 1990). As the sophistication of forest management decision-making increases, the types of questions asked change, and the survey design must be modified to accommodate these changes.

\section{Designing a Regeneration Survey}

The information requirements for forest management decisions are changing, new technology is constantly emerging, and foresters are faced with the continual need to re-assess their regeneration survey practices. How should a survey program be designed?

The first things to consider are the decisions to be made at the forest level, for example, which areas should be treated for weed control or planted. Then the information needed to adequately make those decisions must be specified. Each piece of information becomes a criterion on which the evaluation is made. In many cases these criteria are clearly spelled out, such as in provincial legislation or ground rules in licence agreements. In many cases, however, additional criteria are needed to support operational decision-making. For example, free-growing assessment may only be required to determine whether an area is sufficiently stocked with free-growing trees. The prescription for a release treatment, however, requires information on the major species of competing vegetation, the location of sub-units not requiring treatment, and the potential restrictions on herbicide use. It is also necessary to consider the criteria needed to rank different blocks for treatment. As increasingly sophisticated silviculture planning tools emerge, there will be programs developed to evaluate which blocks should be treated to best benefit the forest as a whole. These programs need more detailed information relating to location, productivity, and species composition.

Some time spent deciding what is the most important information necessary to support decisions is necessary. When those criteria are specified, the data needing collection in the survey can be defined. Data collection should be done in the most efficient method possible and, where appropriate, using a combination of aerial methods, ground methods, and preexisting information. For example, it may be worthwhile doing an aerial reconnaissance flight that would be used for estimating density and stocking, and mapping treatment strata. This could be followed by some detailed stratified field samples to identify free-growing status, growth rate, and soil conditions. Together, the survey results might provide high levels of information at reasonable effort.

Finally, no survey system should be considered universally applicable. The amount of information required will vary depending on circumstances. For example, Ontario uses a prime site key, classing land as quality 1,2 , or 3 . It would be inefficient to use the same regeneration survey system for all three classes of land. For example, class three land may be defined as land that will not be treated silviculturally. In this case, there is little point in collecting detailed data on individual tree growth and competition levels. A two-stage system involving aerial survey of all disturbances followed by ground survey of class 1 and 2 sites might give sufficient information for the decisions necessary to manage the forest. Similary, industrial forests on Southern Vancouver Island would need a greater amount and precision of information for decision-making than those in the mid-coast region. Flexible approaches to survey design are advisable.

\section{Information Needs from Regeneration Surveys}

A decision on the status of regeneration or on what treatment is needed for a given site, requires information. This information represents the criteria by which an evaluation or prescription is made. Where a fixed threshold of success or failure is defined (e.g., in the case of minimum stocking) this is considered a standard. The regeneration survey is designed to collect the data necessary to provide the needed information to the decision-maker. The specification of a regeneration survey system, then, involves defining the information needs, the data needs, and the data collection methodology. However, before examining some specific case studies of regeneration survey techniques, an overview of generic information about regenerated sites is warranted.

\section{Density, Stocking, and Distribution}

One principle question asked is whether there are enough trees established on site to support adequate forest cover in the future stand. Density is a measure of the number of trees per unit area. It is measured by a count of stems in a plot. Density measurement is most useful in evaluating the need for future density control in a stand. Because regeneration is usually not evenly distributed, a measurement called stocking, or the number of well-spaced trees relative to some reference density, is used. In effect, field surveys only count trees of acceptable spacing, say $2.0 \mathrm{~m}$, as a component of stocking. This reference density is defined as the optimum number of well-spaced trees for the site and species concerned. Even the use of stocking, however, may not adequately reflect the distribution of tree stems over an area being surveyed. For example, some areas within the block being surveyed may have full stocking, while others may be unstocked. Using an average stocking value for the block, then, will not adequately represent the fact that a portion of the block is in need of planting. Various methods are available for assessing distribution, including distance measurement between trees, the coefficient of variation, or spatial pattern statistics (Corbett and McCulligh 1990).

\section{Acceptable Crop Species}

On a given site, tree species vary in their potential productivity, value, and susceptibility to risk. In addition, species mixtures differ from monocultures in terms of risk and productivity. Therefore, the definition of an acceptable profile of species on a site requires consideration of ecological suitability, potential productivity and value, the feasibility of management, and stability (Klinka and Feller 1984). Current surveys usually define the acceptable species on a site prior to the survey, and then only count those species when tallying 'acceptable', well-spaced trees. So, for example, a site evaluated for stocking in a jack pine working group would not be considered acceptable if it were fully stocked to trembling aspen. This approach has its limitations. The 
essence of a prescription is an accurate description of the current situation and an evaluation of the alternatives that are available (including doing nothing).

\section{Competition}

The most prevalent source of regeneration failure in Canada is excessive competition from non-crop vegetation. Most survey standards suggest that competition should not be 'unacceptable', or overtopping. Some quantifiable criteria have been suggested (Brand and Weetman 1986; MacDonald et al. 1990; Wagner et al. 1990), but these have not been widely used because the field measurement of competition levels is time consuming. It may be more important to describe these quantifiable models as recognizable conditions in the field and train surveyors to estimate them.

Another problem with competition assessment is a lack of estimation of the dynamics of competition. Thus, while the competitive status of trees may be considered acceptable at the time of survey, there must be consideration of the future development of weed competition. This is particularly important, as weed control treatments should be undertaken before crop trees are suppressed.

\section{Forest Productivity}

One of the more difficult criteria to evaluate is the question of acceptable growth or productivity by the regenerating forest.

Increasingly there is a requirement for regeneration to meet certain height or height growth targets set out in pre-harvest prescriptions or in ground rules for tenure agreements. There has been some recent evidence that height growth shortly after trees have reached breast height is a useful measure of forest productivity (Thrower 1987), but setting standards has been difficult.

\section{Scale}

When describing an area it is necessary to define the scale at which decisions can be made. For example, is it feasible to plant one hectare within a 50-ha block that is otherwise satisfactory? These decisions are often made arbitrarily on a case by case basis, but scale should be recognized as a decision criterion, nevertheless.

\section{Other Values}

As integrated resource management increasingly becomes the norm in Canadian forestry, criteria other than those related to timber production become important. The vegetation on a site must be recognized for its browse potential, and the regeneration must be considered in terms of the value of the future forest for other uses. It may also be necessary to vary the scale of assessment to consider other uses. Questions of how the regenerating stand relates to the cover in adjacent stands may be important in considering wildlife habitat at a landscape level. Small wetlands or pockets of residual timber may be important habitat for some species, and could be missed if the scale of survey is too broad.

The demands being made on current surveys are increasing in complexity. Not only are more surveys being required, but each is more time consuming and more information intensive. There is a growing need to re-examine how we collect survey data, process it into information, and use it to make decisions.

\section{New Approaches to Regeneration Surveys}

\section{The Free-growing Assessment System}

This system, developed over the past five years at the Petawawa National Forestry Institute, is designed to collect field survey data with a portable datalogger and then stream the data through a series of summary and analysis models, finally updating the inventory cover type label in the Geographic Information System database and printing a map of the survey results. The objectives of system development were to demonstrate a biologically meaningful free-growing assessment system, and to demonstrate the linkage of new technologies to facilitate data handling and analysis. An earlier version of the system has been described in some detail (Brand 1988; Brand and Becker 1989).

Briefly, the system uses a systematic field survey to assess total stand density, stocking, growth rate of dominant trees, and the degree of competing vegetation. Data are formatted in the data collection device (Husky Hunter or Dap Microflex) and transferred directly into a summary and analysis routine. This program summarizes stocking by species, age, and origin (planted or natural) and uses a growth projection algorithm to determine whether each tree surveyed is free-growing. Thus the total stocking and the component of stocking that is freegrowing is indicated. In addition, the height growth trend is presented for the dominant trees by age, species, and origin, and the density and size of major competing species are summarized. The spatial pattern of the stocking is analyzed using the I-stat (see Brand 1988 for details) and a file is created giving the $(x, y)$ coordinates and stocking of each plot. This coordinate file is read by a GIS and is used to update the forest cover type label, and to produce a colour-coded map of the survey results. Finally, based on the results of the survey, a series of interpretive comments are printed, indicating potential treatments and the proposed forest cover label with or without weed control. Examples of the output of this program are shown in Tables 1 through 6.

\begin{tabular}{|c|c|}
\hline \multicolumn{2}{|c|}{ Free to grow assessment description } \\
\hline DATE OF DATA COLLECTION & 01-31-1988 \\
\hline LOCATION: & Brandywine Creek \\
\hline ADMINISTRATIVE UNIT: & $92 \mathrm{G} 005-002$ \\
\hline ECOLOGICAL UNIT: & CWHa-01 \\
\hline TALLYMEN: & Paul Rehsler \\
\hline PLOT SIZE (ha): & .005 \\
\hline UTM COORDINATES: & 0489700,5546000 \\
\hline \multicolumn{2}{|c|}{ Species codes and names } \\
\hline$C O D E$ & NAME \\
\hline ABAM & Abies amabilis \\
\hline ALRU & Alnus rubra \\
\hline ALSI & Alnus sinuata \\
\hline CHNU & Chamaecyparis nootkatensis \\
\hline EPAN & Epilobium angustifolium \\
\hline MEFE & Menziesia ferrugina \\
\hline POTR & Populus trichocarpa \\
\hline PSME & Pseudotsuga menziesii \\
\hline PTAQ & Pteridium aquilinum \\
\hline RUSP & Rubus spectabilis \\
\hline SASI & Salix sitchensis \\
\hline SOSI & Sorbus sitchensis \\
\hline TABR & Taxis brevifolia \\
\hline THPL & Thuja plicata \\
\hline TSHE & Tsuga heterophylla \\
\hline TSME & Tsuga mertensiana \\
\hline VAAL & Vaccinium alaskaence \\
\hline VAME & Vaccinium membranaceum \\
\hline
\end{tabular}


Table 2. Stocking summary and estimate of free to grow status by block

Stocking summary and free to grow status for Brandywine Creek as of 01-31-1988

\begin{tabular}{|c|c|c|c|c|c|c|c|}
\hline Species & $\begin{array}{c}\text { Planted/ } \\
\text { natural }\end{array}$ & Age & $\begin{array}{c}\text { Plots } \\
\text { where } \\
\text { present }\end{array}$ & $\begin{array}{l}\text { Total } \\
\text { plots }\end{array}$ & $\begin{array}{c}\text { Total } \\
\text { density }\end{array}$ & $\begin{array}{l}\text { Total } \\
\text { stock }\end{array}$ & $\begin{array}{c}\text { F.T.G. } \\
\text { stock }\end{array}$ \\
\hline \multicolumn{8}{|l|}{ Unit $A:$ Ba type } \\
\hline Abies amabilis & $\mathrm{N}$ & $6+$ & 13 & & & 300 & 245 \\
\hline Chamaecyparis nootkaten & $\mathrm{N}$ & 3 & 2 & & & 18 & 0 \\
\hline Chamaecyparis nootkaten & $\mathrm{N}$ & 5 & 1 & & & 9 & 0 \\
\hline Chamaecyparis nootkaten & $\mathrm{N}$ & $6+$ & 8 & & & 118 & 109 \\
\hline Pseudotsuga menziesii & $\mathrm{N}$ & $6+$ & 1 & & & 9 & 0 \\
\hline Thuja plicata & $\mathrm{N}$ & $6+$ & 2 & & & 64 & 27 \\
\hline Tsuga heterophylla & $\mathrm{N}$ & 4 & 1 & & & 9 & 0 \\
\hline Tsuga heterophylla & $\mathrm{N}$ & $6+$ & 12 & & & 136 & 100 \\
\hline Tsuga mertensiana & $\mathrm{N}$ & $6+$ & 1 & & & 36 & 36 \\
\hline TOTAL FOR UNIT A & & & & 22 & 1636 & 700 & 518 \\
\hline
\end{tabular}

Unit B: NSR

Abies amabilis

Chamaecyparis nootkaten

Chamaecyparis nootkaten

Chamaecyparis nootkaten

Tsuga heterophylla

$\mathrm{N}$
$\mathrm{N}$
$\mathrm{N}$
$\mathrm{N}$

TOTAL FOR UNIT B

\begin{tabular}{rrrrr}
$6+$ & 4 & & 92 & 46 \\
3 & 1 & & 15 & 0 \\
4 & 1 & & 15 & 0 \\
$6+$ & 3 & & 46 & 31 \\
$6+$ & 1 & & 15 & 0 \\
\hline & 13 & 300 & 185 & 77 \\
\hline
\end{tabular}

Unit C: planted PSME

Chamaecyparis nootkaten

Pseudotsuga menziesii

TOTAL FOR UNIT C

$6+$

$6+$

40

\begin{tabular}{lrrrr}
\hline TOTAL FOR UNIT C & 5 & 7200 & 720 \\
\hline \hline STOCKING SUMMARY & 40 & 1147 & 540 \\
\hline \hline
\end{tabular}

Table 3. Distribution statistics, diagnosis, and proposed forest cover type label

\begin{tabular}{lccc}
\hline & & \multicolumn{2}{c}{ Autocorrelation statistics } \\
\cline { 2 - 4 } & Density & Stocking \\
\hline Mean & 1147 & 1147 \\
CV & $328 \%$ & $60 \%$ & 400 \\
I-stat & -.02 & -.04 & $81 \%$
\end{tabular}

Recommendations for block: Brandywine Creek 92G 005-002

Stocking appears insufficient on this site. However, the stocking is not uniformly distributed and may require stratification before treatment. This area appears insufficiently stocked with free-to-grow trees. Stocking of free-growing trees may be unevenly distributed.

Forest cover information

Unit $A$

No treatment: 518 stems/ha FTG

Abies amabilis (5)

Chamaecyparis nootkatensis (2)

Thuja plicata (1)

Tsuga heterophylla (2)

Tsuga mertensiana (1)

With release: 700 stems/ha FTG

Abies amabilis (4)

Unit $B$

No treatment: 77 stems/ha FTG

Abies amabilis (5)

Chamaecyparis nootkatensis (5)

With release: 185 stems/ha FTG

Abies amabilis (5)

Chamaecyparis nootkatensis (5)

Tsuga heterophylla (1)
Unit $C$

No treatment: 720 stems/ha FTG

Pseudotsuga menziesii (10)

With release: 760 stems/ha FTG

Pseudotsuga menziesii (10)

Chamaecyparis nootkatensis (2)

Thuja plicata (1)

Tsuga heterophylla (2)

Tsuga mertensiana (1)

In the example, located near Squamish in coastal British Columbia, a 40 ha clear-cut was surveyed with the freegrowing assessment system. This was part of a trial comparing this system with the conventional B.C. Ministry of Forests field survey system. The output commences with descriptive data on the area being surveyed, followed by a series of species codes that were used in the field to represent the commercial species and competitors (Table 1). The first output from the analysis (Table 2) indicates the stocking by sub-unit. These sub-units are designated by a 'walk-through' of the block prior to survey commencement. Table 2 indicates the total density of trees, the stocking of trees 
Table 4. Summary of height growth and projected height growth

Total mean tree height free to grow trees for Brandywine Creek as of 01-31-1988

\begin{tabular}{|c|c|c|c|c|c|c|c|}
\hline & \multicolumn{7}{|c|}{ Season of growth } \\
\hline & 1982 & 1983 & 1984 & 1985 & 1986 & 1987 & $\begin{array}{c}1988 \\
\text { (projected) }\end{array}$ \\
\hline \multicolumn{8}{|l|}{ Unit A: Ba type } \\
\hline $\begin{array}{l}\text { Natural Abies amabilis } \\
\text { Age }=6+ \\
\text { Natural Chamaecyparis nootkatensis }\end{array}$ & 1.81 & 1.95 & 2.06 & 2.15 & 2.33 & 2.53 & 2.68 \\
\hline $\begin{array}{l}\text { Age }=6+ \\
\text { Natural Thuja plicata }\end{array}$ & 1.40 & 1.56 & 1.74 & 1.92 & 2.14 & 2.42 & 2.67 \\
\hline $\begin{array}{l}\text { Age }=6+ \\
\text { Natural Tsuga heterophylla }\end{array}$ & 0.81 & 0.95 & 1.16 & 1.30 & 1.54 & 1.78 & 1.98 \\
\hline $\begin{array}{l}\text { Age }=6+ \\
\text { Natural Tsuga mertensiana }\end{array}$ & 1.72 & 1.86 & 1.99 & 2.13 & 2.29 & 2.48 & 2.66 \\
\hline Age $=6+$ & 1.52 & 1.64 & 1.75 & 1.87 & 1.96 & 2.07 & 2.19 \\
\hline \multicolumn{8}{|l|}{ Unit $B: N S R$} \\
\hline $\begin{array}{l}\text { Natural Abies amabilis } \\
\text { Age }=6+ \\
\text { Natural Chamaecyparis nootkatensis }\end{array}$ & 1.62 & 1.81 & 1.95 & 2.01 & 2.09 & 2.25 & 2.36 \\
\hline Age $=6+$ & 0.49 & 0.61 & 0.74 & 0.88 & 1.12 & 1.35 & 1.55 \\
\hline \multicolumn{8}{|l|}{ Unit C: planted PSME } \\
\hline $\begin{array}{l}\text { Natural Chamaecyparis nootkatensis } \\
\text { Age }=6+ \\
\text { Planted Pseudotsuga menziesii }\end{array}$ & 0.46 & 0.62 & 0.80 & 0.98 & 1.14 & 1.34 & 1.54 \\
\hline Age $=6+$ & 0.48 & 0.75 & 0.95 & 1.21 & 1.54 & 1.93 & 2.28 \\
\hline
\end{tabular}

Table 5. Summary of competing vegetation by growth class

Summary of competing vegetation for Brandywine Creek as of $01-31-1988$

\begin{tabular}{|c|c|c|c|}
\hline \multirow[b]{2}{*}{ Species } & \multirow[b]{2}{*}{$\begin{array}{l}\text { Frequency } \\
\text { (\% trees) }\end{array}$} & \multicolumn{2}{|c|}{$\begin{array}{l}\text { Average canopy } \\
\text { height }(\mathrm{m})\end{array}$} \\
\hline & & Current & $\begin{array}{c}\text { Projected } \\
1988\end{array}$ \\
\hline $\begin{array}{l}\text { Class 1: Herbaceous } \\
\text { Epilobium angustifol }\end{array}$ & 9.3 & 1.35 & 1.35 \\
\hline $\begin{array}{l}\text { Class 2: Low woody brus } \\
\text { Alnus sinuata } \\
\text { Menziesia ferrugina } \\
\text { Salix sitchensis } \\
\text { Sorbus sitchensis } \\
\text { Vaccinium membranace }\end{array}$ & $\begin{array}{r}1.9 \\
2.8 \\
5.6 \\
1.9 \\
13.0\end{array}$ & $\begin{array}{l}4.03 \\
1.7 \\
3.58 \\
1.54 \\
1.09\end{array}$ & $\begin{array}{l}4.54 \\
1.82 \\
3.78 \\
1.64 \\
1.23\end{array}$ \\
\hline $\begin{array}{l}\text { Class 3: Tree-like brush } \\
\text { Populas trichocarpa }\end{array}$ & 1.9 & 9.25 & 9.56 \\
\hline
\end{tabular}

(i.e., well-spaced relative to a reference density of $1000 \mathrm{stems} / \mathrm{ha}$ ), and the stocking of trees classified as freegrowing by the model. It can be seen that a portion of the area, sub-unit B, is insufficiently restocked and may require fill-planting or rehabilitation. In Table 3 , statistics are presented to assist the interpretation of the distribution of the trees. For each of density, stocking, and free-growing stocking, the mean, coefficient of variation (variance divided by mean), and spatial autocorrelation statistics are presented. It can be seen that stocking is positively autocorrelated, flagging the fact that sub-unit B represents a large unstocked area in the block surveyed. Following this, a series of comments are printed based on a rulebase that interprets outputs from this table. The recommendations suggest that stocking is generally poor and that it is not uniformly distributed. This might signal the analyst to print out a map showing the pattern of plots with insufficient stocking. The forest cover information is extracted from the stocking table and indicates the forest cover label for the sub-units if no treatment were undertaken, and if a weed control treatment were undertaken. No blocks are actually classified as NSR, as it may be decided that further treatment is not cost-effective.

The height growth summary (Table 4 ) indicates the relative productivity of the species found on this site. The planted Douglas-fir are outperforming the naturally established regeneration based on current growth rate. Among naturally regenerated species, yellow cedar (Chamaecyparis nootkatensis) is currently the most productive. The summary of competing vegetation (Table 5) indicates the frequency of each species based on growth type, and indicates the current and projected height of the vegetation. This information is useful in designing vegetation management if desired, or for evaluating browse quality on the block. Finally, Table 6 indicates the UTM co-ordinates for each plot, followed by total stocking and free-growing stocking. This information can be stored in a GIS layer and produced as thematic maps (Brand 1988).

The evaluation of the free-growing system indicated a need for the data collection software to be "ruggedized'. As a prototype system there were too many bugs and awkward routines. In some cases, data were lost due to keying errors and plots had to be re-keyed in the field. This, plus the requirement for additional field measurements beyond that needed for the conventional survey, led to a tripling in the time needed to complete a given survey. In 1990, the software was revised in accordance with the evaluation comments, and a new trial will be undertaken in future.

\section{Use of Aerial Survey Methods for Stocking Survey}

Aerial reconnaisance can be a useful tool for conducting regeneration surveys, particularly as it gives an overview of the entire survey block. This helps stratify zones of 


\begin{tabular}{|c|c|c|c|c|}
\hline & & Plot coord & & \\
\hline Plot & $\mathbf{X}$ & $\mathbf{Y}$ & Stocking & $\begin{array}{c}\text { FTG } \\
\text { stocking }\end{array}$ \\
\hline 001 & 489700 . & 5545920. & 5 & 5 \\
\hline 002 & 489600 . & 5545920. & 2 & 0 \\
\hline 003 & 489600 . & 5545990 . & 4 & 3 \\
\hline 004 & 489600. & 5546080 . & 5 & 5 \\
\hline 005 & 489600 . & 5546160 . & 5 & 2 \\
\hline 006 & 489600 . & 5546240 . & 1 & 0 \\
\hline 007 & 489600. & 5546320 . & 0 & 0 \\
\hline 008 & 489700 . & 5546320 . & 0 & 0 \\
\hline 009 & 489700 . & 5546240 . & 4 & 2 \\
\hline 010 & 489700 . & 5546160. & 5 & 4 \\
\hline 011 & 489700. & 5546080. & 2 & 0 \\
\hline 012 & 489800 . & 5545920 . & 4 & 4 \\
\hline 013 & 489800 . & 5546080 . & 6 & 3 \\
\hline 014 & 489800 . & 5546170 . & 2 & 2 \\
\hline 015 & 489800 . & 5546240 . & 2 & 0 \\
\hline 016 & 489800 . & 5546320. & 4 & 4 \\
\hline 017 & 489800 . & 5546400 . & 3 & 3 \\
\hline 018 & 489800 . & 5546480. & 2 & 0 \\
\hline 019 & 489800 . & 5546580. & 2 & 1 \\
\hline 020 & 489800 . & 5546640 . & 1 & 0 \\
\hline 021 & 489900. & 5546640 . & 3 & 2 \\
\hline 022 & 489900 . & 5546560. & 1 & 0 \\
\hline 023 & 489900. & 5546480 . & 4 & 3 \\
\hline 024 & 489900 . & 5546400 . & 1 & 0 \\
\hline 025 & 489900 . & 5546320 . & 0 & 0 \\
\hline 026 & 489900 . & 5546240 . & 0 & 0 \\
\hline 027 & 489900. & 5546160. & 2 & 1 \\
\hline 028 & 489900 . & 5546080 . & 0 & 0 \\
\hline 029 & 489900 . & 5546000. & 5 & 5 \\
\hline 030 & 489900 . & 5545960 . & 4 & 4 \\
\hline 031 & 489900. & 5545920. & 5 & 4 \\
\hline 032 & 489950 . & 5545920. & 0 & 0 \\
\hline 033 & 490000 . & 5545920 . & 5 & 5 \\
\hline 034 & 490000. & 5546080 . & 0 & 0 \\
\hline 035 & 490080. & 5546140. & 0 & 0 \\
\hline 036 & 490021. & 5546321 . & 3 & 3 \\
\hline 037 & 490021. & 5546401 . & 5 & 4 \\
\hline 038 & 490021. & 5546481 . & 5 & 5 \\
\hline 039 & 490021. & 5546561. & 4 & 4 \\
\hline 040 & 490021. & 5546641. & 2 & 2 \\
\hline
\end{tabular}

differing regeneration (e.g., the sub-units of the free-growing assessment system described above) and it may be possible to identify zones where remedial action such as fill-planting or thinning is necessary. The required scale and source of imagery depend on the management decisions that are to be made.

At higher resolutions, aerial surveys are capable of acquiring quantitative data suitable for statistical sampling . Large scale photography (LSP) at scales of 1:500 to 1:1000 is generally effective for estimating stocking and has had varying degrees of success in assessing species, competition, and height (Ball and Kolabinski 1979; Goba et al. 1982; Hall 1984). Hall (1984) found that with 1:580 LSP, tree heights had to be greater than $90 \mathrm{~cm}$ to achieve good (defined as 90\% correct) species identification. Assessment of both competition and stocking is often difficult, as overtopping vegetation can obscure the crop trees and make aerial estimation difficult. To overcome this problem, it is recommended that areas be flown in the spring, before leaf flush. If competition problems also need to be identified, a second flight in midsummer can be useful.

Regeneration is a dynamic phenomenon and, ideally, one would like a dynamic inventory. In some cases, a block may need to be surveyed several times before it has reached 20 years of age. Normally, growth is projected from the most recent field survey data, assuming trees identified will remain free-growing and alive. However, even with projection models, it is desirable to check the status of regeneration periodically. Aerial surveys are an inexpensive method of monitoring the growth of young stands and determining whether they are meeting performance expectations. For example, a block may have been marginally classified as freegrowing, and a check after 2 or 3 years would clarify whether predicted stocking targets had, in fact, been achieved. Aerial surveys are promising for this role because they are less costly and labour intensive than resampling on the ground. They are particularly beneficial in areas with poor access, such as the large areas burned in Manitoba in 1989. Satellite data can also play a role in regeneration monitoring; Leckie (1990) describes a possible method using winter Landsat imagery.

The most effective use of aerial surveys may be in combining a low resolution overview image with a set of higher resolution sub-images that could be used to measure more difficult features of the regeneration. Kirby and Hall (1979) and Goba et al. (1982) describe such systems using different scales of photography acquired simultaneously from the same aircraft. Digital remote sensing technology could also be used, incorporating satellite data and multispectral data at varying resolutions from airborne scanners such as the MEIS II (Multi-spectral Electro-Optical Imaging Scanner) (McColl et al. 1984). With Inertial Navigation and/or Global Positioning Systems in the aircraft, it is possible to achieve high positional accuracy automatically and relate results to inventory and other survey information residing on a GIS.

The use of airborne scanner data is a new approach not well examined, although it has been studied for juvenile stand assessment in British Columbia with some success (Kneppeck and Ahern 1987). The advantages of digital multispectral sensors include their potential for automating the assessment of regeneration (e.g., tree counting), locating the data accurately, and efficiently inputting results into a GIS. Alternatively, the multispectral and digital format permit manipulation of the imagery to aid visual interpretation of certain features of the regeneration. For example, one can choose spectral band combinations to optimize differences between regeneration and background vegetation, slash, or soil. Also, the ability to digitally enlarge or zoom parts of the image aids interpretation. Recent technological developments make such applications worth investigating. Linear array imagers such as the MEIS II permit very high resolution $(30-40 \mathrm{~cm})$ multispectral imagery to be acquired. As well, the MEIS II has stereo imaging capabilities so that tree height can be estimated and tree shape or form can be used to aid single tree detection.

Data from three MEIS II flights were used to evaluate the potential of MEIS imagery for estimating the stocking of young plantations. These data were collected over the Sturgeon plantation area of the Petawawa National Forestry Institute research forest near Chalk River, Ont. (approximate latitude $45^{\circ} 57^{\prime} 50^{\prime \prime}$ and longitude $\left.77^{\circ} 34^{\prime} 45^{\prime \prime}\right)$. Fourteen jack pine (Pinus banksiana) and Scots pine (Pinus sylvestris) plantations ranging in age from 3 to 14 years and in height from 0.8 to $6.4 \mathrm{~m}$. were studied (Table 7). Ground cover included grasses, sedges, and some herbaceous plants. The imagery 


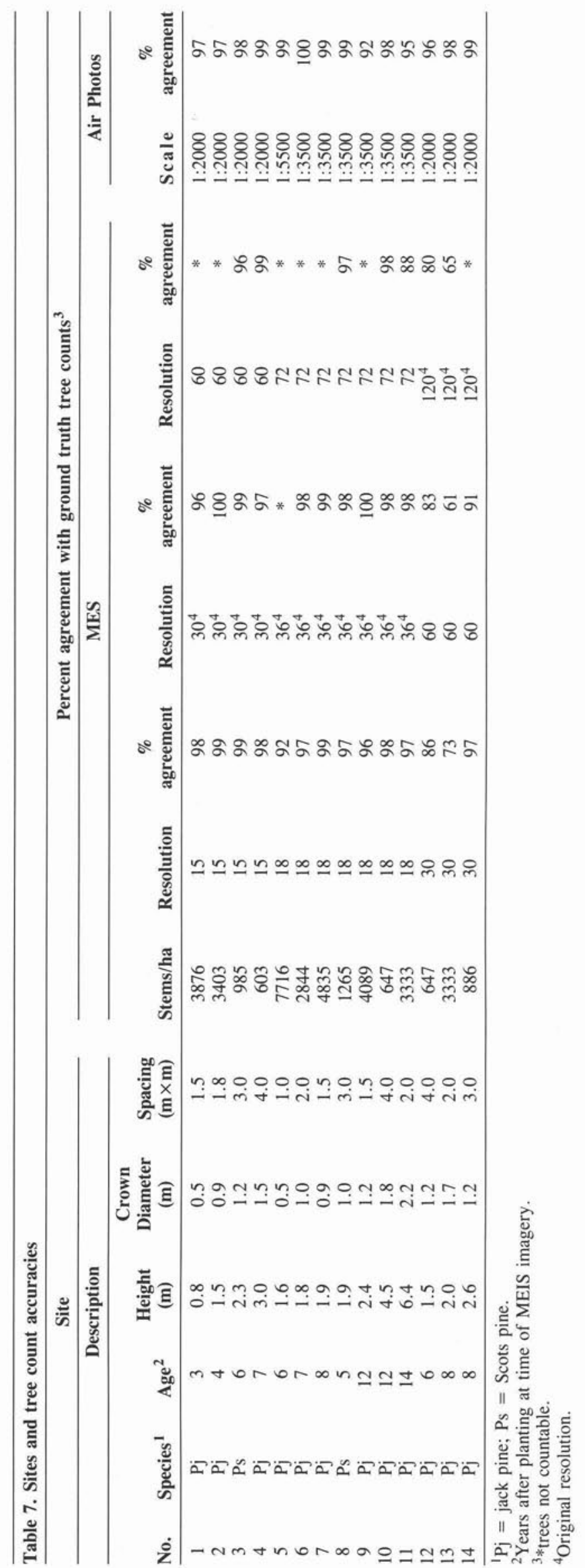

Table 8. Spectral bands of MEIS data

\begin{tabular}{|c|c|c|c|c|c|}
\hline \multicolumn{6}{|c|}{ Data set } \\
\hline \multicolumn{3}{|c|}{ November 1982 MEIS } & \multicolumn{3}{|c|}{ August 1988 MEIS } \\
\hline \multicolumn{3}{|c|}{ Band } & \multicolumn{3}{|c|}{ Band } \\
\hline No. & Centre (nm) & Range (nm) & No. & Centre (nm) & Range (nm) \\
\hline 1 & 444.87 & $430.0-459.6$ & 1 & 448.9 & $433.6-464.2$ \\
\hline 2 & 521.2 & $507.2-535.2$ & 2 & 548.4 & $532.5-564.3$ \\
\hline 3 & 590.2 & $573.9-606.6$ & 3 & 640.2 & $621.7-658.7$ \\
\hline 4 & 672.9 & $658.2-687.6$ & 4 & 675.1 & $655.3-694.9$ \\
\hline \multirow[t]{2}{*}{5} & 870.8 & $843.6-897.9$ & 5 & 873.4 & $846.1-900.7$ \\
\hline & & & 6 & 1017.5 & $962.8-1017.5$ \\
\hline
\end{tabular}

Note: Bands 5, 1 and 2 or 5, 3 and 2 displayed as red, green and blue were used for the November 1982 data analysis and bands 2.5 and 4, respectively, were used for the August, 1988 data analysis.

used was acquired at $30 \mathrm{~cm}$ and $120 \mathrm{~cm}$ pixel resolution in November, 1982, and at $36 \mathrm{~cm}$ in August, 1988. Table 8 gives the spectral bands for each data set. Figures 1 and 2 give an example of the imagery and ground sites. Regeneration stocking was also assessed with aerial photography and ground sampling. Normal colour 1:2000 scale photographs, taken in June, 1982 were used for comparison with the November 1982 imagery. Colour infrared 1:3500 photos taken in November 1987, plus black and white 1:5500 photos taken in July 1989 were used to compare with the August 1988 MEIS imagery. Results of MEIS, photography, and field tree counts were compared. Interpretations of MEIS imagery were done on what were determined to be the best combination of contrast enhanced wavelength bands (Table 8), displayed on a television monitor. The photographic prints were viewed through either a $2 \times$ or $8 \times$ magnification stereoscope. MEIS imagery was resampled to one half and double the original resolution for the 30- and $36-\mathrm{cm}$ data and to one-half and one-quarter the original resolution for the $120-\mathrm{cm}$ data. Computer resampling of MEIS imagery to a higher resolution (e.g. $36 \mathrm{~cm}$ to $18 \mathrm{~cm}$ ) by interpolation among adjacent pixels, in this case by cubic convolution, improved image clarity and object detection (even though it was essentially the same data). Object edges became less "blocky" in appearance and more readily detectable.

There was good agreement among the air photos, high resolution MEIS, and ground counts of number of trees (Table 7). Average agreements were $97.6 \%$ and $94.7 \%$ for the photographs and MEIS imagery, respectively, with no consistent trend of over or underestimating counts. If only the MEIS data with original resolution of 30 or $36 \mathrm{~cm}$ is considered, agreement was $97.2 \%$. Agreement of the MEIS and air photo counts was $95.8 \%$; $97.7 \%$ if the $120 \mathrm{~cm}$ resolution data are not included.

At the highest resolution, all tree sizes and densities tested (Table 7) were accurately detectable. It was noted, however, that for several additional plantations of less than $1.0-\mathrm{m}$ spacing, trees were not countable. Detectability depended on the combined effects of tree size (crown diameter and to some extent height), density, and resolution. For example, comparing sites 1 through 4 , counting accuracy was good for all at $30 \mathrm{~cm}$ resolution, but the smaller trees of sites 1 and 2 were not countable at $60 \mathrm{~cm}$ resolution. Site 5 , with small closely spaced trees, was not countable at $36 \mathrm{~cm}$ resolution, whereas the slightly larger and wider spaced trees of sites 6 and 7 were. 


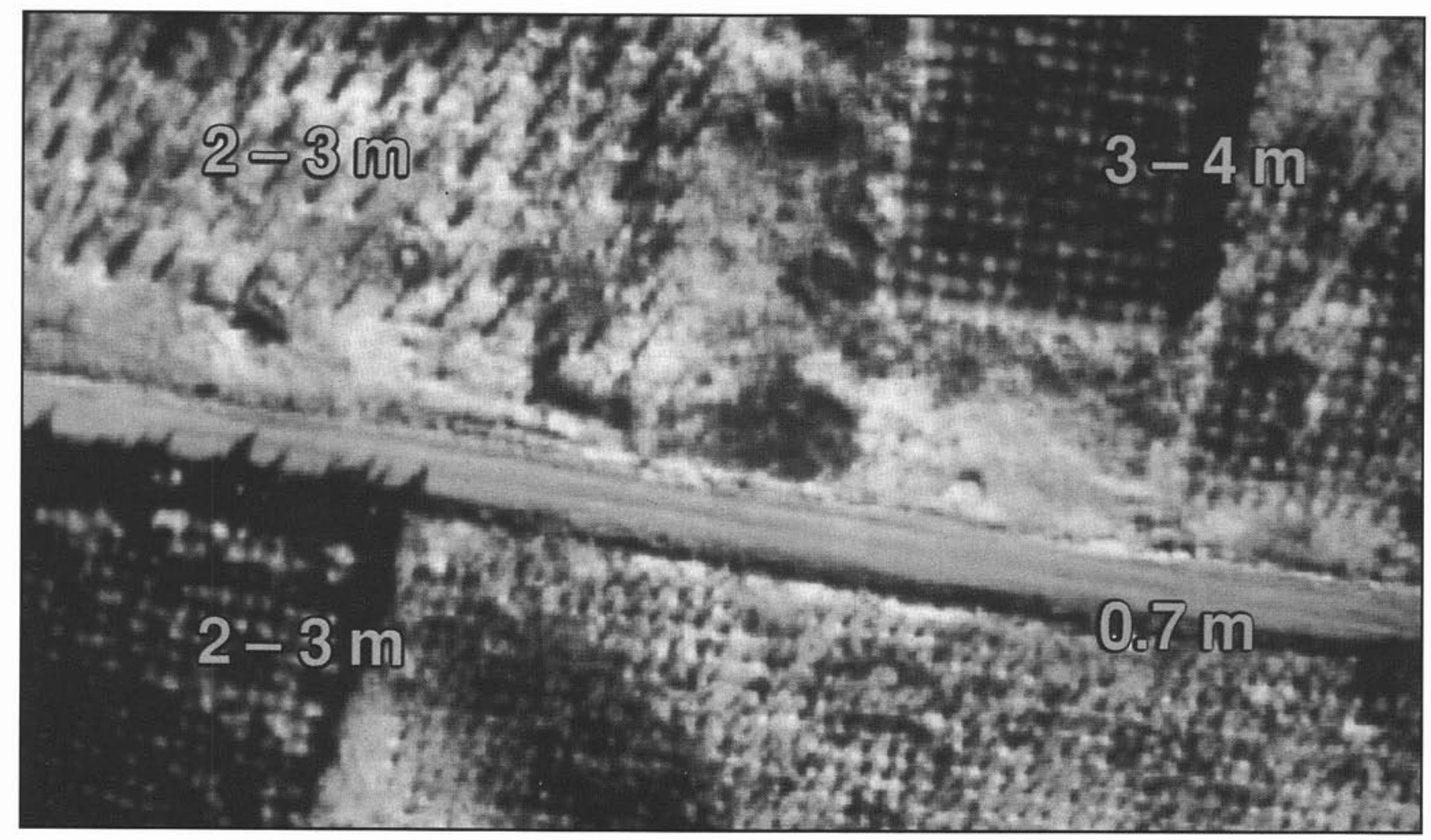

Figure 1. Thirty centimetre resolution MEIS II image of jack pine plantations; bands 5, 3, and 2 displayed as red, green, and blue.

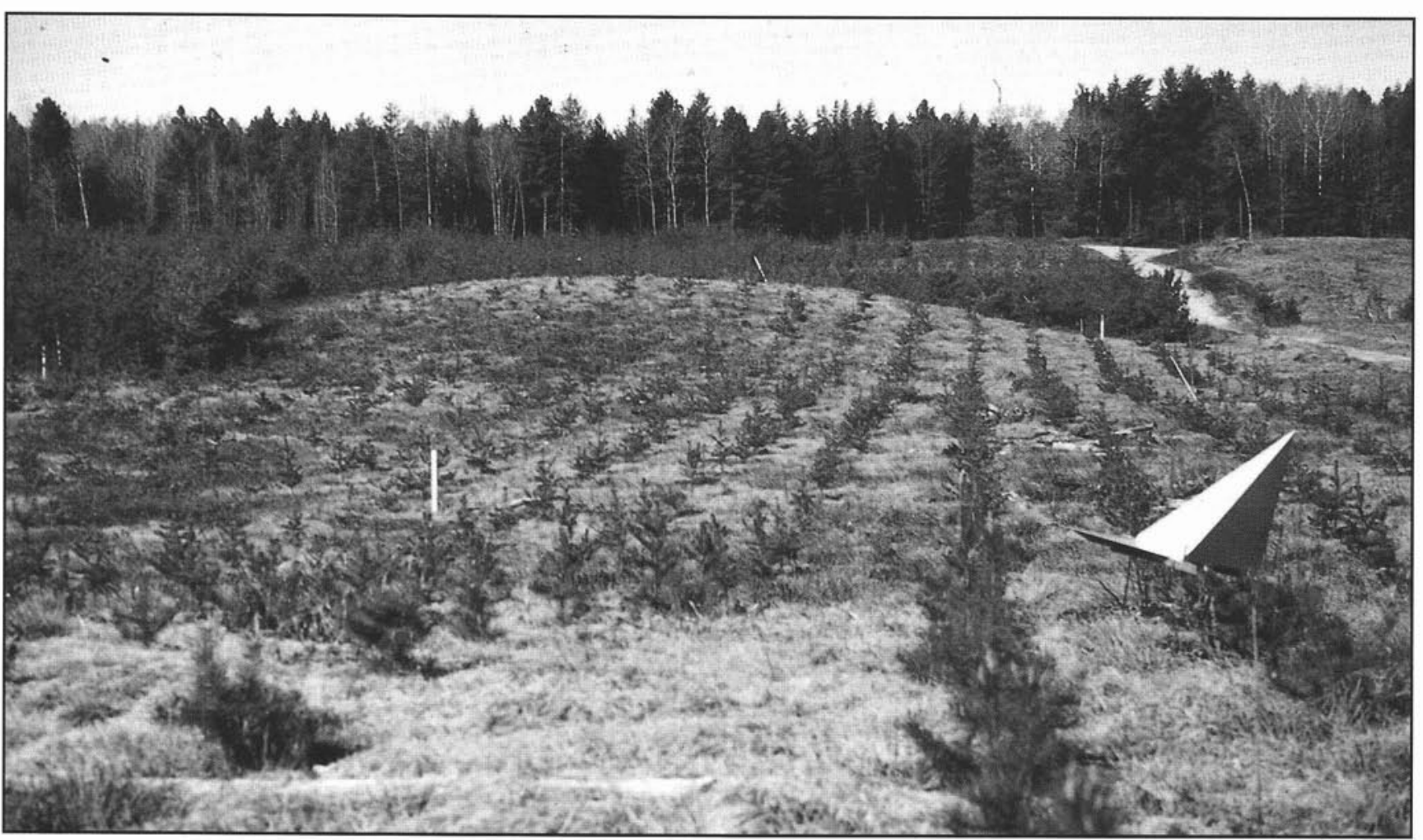

Figure 2. Ground photo of 0.7-m-high jack pine plantation from Figure 1. 
A further point regarding resolution is that, although accuracy sometimes remained constant over the ranges of resolution examined, ease of interpretation did not. The highest resolutions allowed fast, confident counting. The lower resolutions generally took longer, frequently requiring recounting due to loss of position and blurring of tree boundaries. It is also important to note that resampling to higher resolution than the original data improved ease of counting and, in the case of $120 \mathrm{~cm}$ data, accuracy.

Detecting and counting trees on very high resolution MEIS imagery was sufficient for operational stocking surveys of several planted conifer regeneration sites. Accuracy for sites with natural regeneration or with greater herbaceous, shrub, or hardwood competition was uncertain, but is expected to be poorer. Results indicate that for the site parameters examined (e.g. minimum tree height of $0.8 \mathrm{~m}$ with a spacing of $1.5 \mathrm{~m}$ ), a resolution of approximately $30-40 \mathrm{~cm}$ will be required. Resampling to double the resolution improved clarity and ease of interpretation, although accuracy was not increased. Detection and counting of trees was much easier and faster using the MEIS imagery displayed on the screen than it was on the air photos used in this study, even though both were found to be equally accurate. The lack of stereo viewing of the MEIS data was not a factor. The ability to choose spectral bands and enhance the contrast of each band to optimize tree detectability was important to increasing the capability of the MEIS imagery. The ability to zoom and use the screen cursor to improve interpreter-image interaction and counting ease was also important since losing count position, especially in dense stands, was a major time related factor when using the aerial photographs.

\section{Conclusions}

Regeneration surveys must be looked upon as a tool to support decisions on forest land classification and treatment allocation. Design of surveys should take into account the information needed to make decisions and not simply determine if legislated standards have been met. New approaches to survey design include systematizing data collection and analysis, use of new descriptive criteria, and use of aerial survey technology. The specific features of a given survey should be flexible and a function of management requirements.

\section{References}

Armson, K.A., F.C. Robinson, and J.E. Osborn. 1980. Forest management manual for the province of Ontario. Min. Nat. Resources, Forest Resources Group, Toronto, Ont.

Ball, W.J. and V.S. Kolabinski. 1979. An aerial reconnaisance of softwood regeneration on mixedwood sites in Saskatchewan. Env. Can. Can. For. Serv., Inf. Rep. NOR-X-216.

Brand, D.G. 1988. A systematic approach to assess forest regeneration. For. Chron. 64: 414-420.
Brand, D.G. and A. Becker. 1989. A framework for integrating silviculture survey with data analysis, planning, and database update. In J. McPhalen, Proc. GIS'90 A Wider Perspective, Reid Collins-Forestry Canada, Vancouver, B.C.

Brand, D.G. and G.F. Weetman. 1986. Standards for regeneration establishment in Canada: A case study for Douglas-fir. For. Chron. 62: 84-90.

British Columbia Ministry of Forests. 1990. Silviculture Manual: Instructions to Forest Officers in Silviculture. B.C. Min. For. Silviculture Branch, Victoria, B.C.

Corbett, P. and McCulligh. 1990. Comparative analysis of regeneration assessment techniques - A literature review. Ont. Min. Natural Resources NW Ont. For. Tech. Dev. Unit Rep.\#51.

Curry, S. 1990. The challenge of substantiating improved yields from a managed forest. In D.G. Brand, (ed). Canada's Timber Resources. For. Can. Inf. Rep. (in press).

Goba, N.B., S. Pala, and J. Narraway. 1982. An instruction manual on the assessment of regeneration success by aerial survey. Ont. Centre for Remote Sensing, Min. Nat. Resources, Toronto, Ont.

Hall, R.J. 1984. Use of large scale aerial photographs in regeneration assessments. Can. For. Serv., Inf. Rep. NOR-X-264.

Kirby, C.L. and R.J. Hall. 1979. The large-scale photo sampling system at the Northern Forest Research Centre. In: Proc. Practical Applications of Remote Sensing to Timber Inventory. Edmonton, Alberta. For. Can. Inf. Rep. NOR-X-224.

Klinka, K. and M.C. Feller. 1984. Principles used in selecting tree species for regeneration of forest sites in southwestern British Columbia. For. Chron. 60: 77-85.

Kneppeck, I.D. and F.J. Ahern. 1987. Evaluation of a multispectral linear array sensor for assessing juvenile stand conditions. Proc. 21st International Symp. Remote Sensing of Environment, Ann Arbor, Michigan.

Leckie, D.G. 1990. Advances in remote sensing technologies for forest surveys and management. Can. J. For. Res. 20: 464-483.

MacDonald, B., D.M. Morris, and P.L. Marshall. 1990. Assessing components of competition indices for young boreal plantations. Can. J. For. Res. 20: 1060-1068.

McColl, W.D., R.A. Neville, and S.M. Till. 1984. Multi-detector electro-optical imaging sensor MEIS II. pp. 71-79. In: Proc. 8th Can. Symp. on Remote Sensing, Montreal, Que.

New Brunswick Department of Natural Resources. 1982. Forest Management Manual for Crown Lands. NB Dept. Nat. Resources, Fredericton, N.B.

Pearce, C. 1990. Monitoring regeneration programs. In: D.P. Lavender, et al. (eds.) Regenerating British Columbia's Forests. University of British Columbia Press, Vancouver, B.C.

Thrower, J.S. 1987. Growth intercepts for estimating site quality of young white spruce plantations in north central Ontario. Can. J. For. Res. 17: 1385-1389.

Wagner, R.G., T.D. Peterson, D.W. Ross, and S.R. Radosevich. 1989. Competition thresholds for the survival and growth of ponderosa pine seedlings associated with woody and herbaceous vegetation. New Forests 3: 151-170. 